\title{
The role of mock job interviews in enhancing sport students' employability skills: An example from the UK
}

Rhiannon Lord

Ross Lorimer

John Babraj

Ashley Richardson

This is the accepted manuscript (C) 2019, Elsevier Licensed under the Creative Commons AttributionNonCommercial-NoDerivatives 4.0 International.

The published article is available from:

https://doi.org/10.1016/j.jhlste.2019.04.001 
1 The role of mock job interviews in enhancing sport students' employability skills: An example from

2 the UK

3

4 Rhiannon Lord ${ }^{1}$, Abertay University, Dundee, UK

5 Ross Lorimer, Abertay University, Dundee, UK

6 John Babraj, Abertay University, Dundee, UK

7 Ashley Richardson, Abertay University, Dundee, UK

8

9

10 Abstract

11 Although graduate employability is an increasingly important issue, job interview formats and techniques specific to sport students' prospective careers are not explicitly taught, practiced or assessed. Yet, successful interviews are pivotal in transitioning from education to employment. We report on a teaching intervention with final year sport students who undertook mock job interviews as an assessment. Evaluative data suggests students initially felt underprepared for job interviews. The assessment allowed students to adapt and practice their skills in this context and receive feedforward-focused feedback. From this work, we provide recommendations on how this activity might be implemented in other higher education curricula.

Keywords: Graduate employability skills, job interviews, interview-based assessment, experiential learning, sport student experience, enhancing student skills

\footnotetext{
${ }^{1}$ Corresponding Author is Dr Rhiannon Lord. R.Lord@abertay.ac.uk. Division of Sport and Exercise Sciences, Kydd Building, Level 5, Abertay University, Bell Street, Dundee, DD1 $1 \mathrm{HG}$.
} 


\subsection{Introduction}

2 Graduate employability is a global issue that spans across subject areas and academic disciplines

3 (Jackson and Bridgstock, 2018; Kalfa \& Taksa, 2015; Pavlin \& Svetlik, 2014). Rising university fees

4 and unstable job markets have led to graduates' attainment of a full-time graduate-level job being a

5 dominant indicator of success (Whiteley, 2016). Indeed, policymakers across the globe are

6 increasingly using graduate employment as a measure of the value of graduates and Higher

7 Education Institutions (HEIs) (Jackson \& Bridgstock, 2018). The Graduate Outcomes Survey (GOS) in

8 Australia and the Destination Leavers from Higher Education survey (DLHE) in the UK are both

9 examples of this activity. Thus, HEls are increasingly expected to prepare prospective graduates for

10 graduate-level employment, offering opportunities to develop work-based knowledge, skills and personal attributes which benefit students, the workforce, communities and the economy (Taylor, 2017; York, 2004). Many HEls in Europe, North America, Australia, and New Zealand have adopted a work-integrated learning (or work-based learning) approach, where employability skills and experiences are embedded into course curricula to prepare graduates for the workplace (Clarke, 2018; Jackson and Collings, 2018). In the UK, where this study took place, graduate employability has been the focus of government policy for the past 20 years. The Dearing Report (1997), Higher Ambitions (The Department of Business Innovation and Skills, 2009) and the Wilson Review (Wilson, 2012), for example, all sought to develop the link between (prospective) graduates and employers. Subsequently, Advance HE, the organisation for supporting HEls practice in the UK, promotes the inclusion of employability skills that are embedded into and across undergraduate curricula rather than confining support and employability skills to careers departments in HEls (Pegg, Waldock, Hendy-Isaac \& Lawton, 2012). This approach has, in turn, been validated by sector-wide schemes such as Higher Educations Achievement Reports (HEAR) which offer a record of students' universityendorsed extracurricular activities. Yet graduates often fall short of employer expectations, not just in the UK, but more broadly (Moore \& Moreton, 2017; Tran, 2015; Tsitskari, Goudas, Tsalouchou \& Michalopoulou, 2017). They want graduates who are fully prepared to enter their workforce; without any additional training or experience (Clarke, 2018; Jackson \& Collings, 2018).

A small collection of survey-based studies have captured student experiences of work-based learning as preparation for the workplace (e.g., Atfield \& Purcell, 2010; Cronin \& Lowes, 2016; Jackson, 2015; Jackson \& Wilton, 2017). Collectively, these studies have identified that students learn employability skills in the classroom, but work placements provide opportunities to practice and develop these skills. However, students encounter a wide-range of problems while out on placement (e.g., working and communicating with others, self-management, lacking confidence to challenge instructions or decisions, feeling inadequate or isolated). However, across the literature, we hear very little about how graduates prepare to navigate the pivotal jump from higher education (HE) to graduate employment - the job interview - and how HE curricula prepare student for this. Given the centrality of job interviews in achieving (graduate) employment, it seems odd that this is not explicitly part of HE curricula, especially within the contemporary global emphasis on graduate employability as a key marker for HEls value and success. Therefore, the purpose of this paper is to start discussion and call for further research on how we can teach undergraduate (sport) students to prepare for job interviews in their field. Thus, our contribution is three-fold. First, we provide evidence that undergraduate students feel underprepared to take part in job interviews at the end of their degree. Second, we present an evaluation of a small-scale teaching intervention that gave students the opportunity to practice and receive feedback on their job interview skills. Finally, we offer recommendations for other teaching practitioners in the fields of hospitality, leisure, sport and tourism, on how they might implement mock job interviews as a form of assessment within their curricula. 


\subsection{Graduate job interviews}

Graduate recruitment processes are commonly split into two main stages (Humberg \& Van der Velden, 2015). First, employers screen potential candidates' CVs to decide which applicants to invite to interview. Second, employers interview applicants to assess their skills and knowledge and they use this information to determine their final hiring decision. In some industries interviews can be more specific to the needs of the employer. For example, physical education teacher interviews often require a traditional interview with a panel representing the employer (i.e., the school) and then a practical demonstration of teaching ability. A similar interview format is often used for entry onto postgraduate teaching courses required for sport students who want to pursue a career in teaching.

Over the past 20 years, a plethora of research has looked at what informs employers' hiring decisions. For example, psychological studies of employer behaviour have identified various forms of (unconscious) bias when employers interview job applicants (e.g., Houge, Levashina \& Hang, 2013; Kirschenman \& Neckerman, 1991; Koch, D’Mello \& Sackett, 2015; Lindsay et al., 2015; McCarthy, Van Iddelinge \& Champion, 2010; Wolgast, Björklund \& Bäckström, 2018). Studies have also looked at the skills employers look for at various stages of the job interview. Humberg and Van der Velden (2015) found that industry-specific skills and knowledge (e.g., an undergraduate degree, additional qualifications and work experience) were essential in employers' decisions to shortlist candidates. Employers assume candidates with these skills will have minimal training costs and short(er) adjustment periods. However, at interview, candidates' professional expertise, that is knowledge and skills to solve problems in occupational contexts, and interpersonal skills are most influential in employers' decisions to hire a candidate (Humberg \& Van der Velden, 2015; Rivera, 2015).

For undergraduates, the latter stage of the recruitment process, the job interview, is an alien and anxiety-provoking environment (Wittmann-Price, Price, Graham \& Wilson, 2016). Interviews are high pressure situations that often produce undesirable behavioural 'slips' (e.g., stuttering and memory 'blanks') due to anxiety (Feeney, McCarthy \& Goffin, 2015). Yet, there is little information in the pedagogical literature on how to explicitly prepare undergraduates for this inevitable experience, particularly in the field of sport; something this paper aims to address.

\subsection{The complexities of preparing sport students for job interviews}

Employability research on graduates from sport degree programmes has traced them to various careers and industries, often away from sport and exercise. For example, Minten and Forsyth (2014) found that just $43 \%$ of graduates were in sport-related employment 10 years after graduating. The majority were in Physical Education (PE) teaching or sport development roles. The remaining 57\% were employed in various industries and sectors including the armed and emergency services, youth and social work, marketing and the civil service. Similar patterns have been reported by Sleap and Reed (2006) and the Association of Graduate Careers Advisory Services (AGCS)(2007). This is not necessarily because graduates were unable to obtain sport-related employment. Many undergraduate sport students select the subject area because of personal interests, rather than specific vocational reasons (Keech, 2006) and this is not just isolated to sport students (Atfield \& Purcell, 2010). Thus, given the breath of employment sport students enter, preparing them for job interviews and employment more generally is particularly challenging. 


\subsection{Experiential learning for sport students}

Experiential learning is central to developing graduate employability skills (Helyer \& Lee, 2014) particularly in undergraduate sport students (Cronin \& Lowes, 2016; Foster \& Dollar, 2017; Sato \& Laughlin, 2018; Sauder \& Davis, 2017). This is the process of linking theory-based learning to practical application of this knowledge. With critical reflection and practice, this leads to the development of a skill or skill-set. Helyer (2010, p.21) explains 'learning and doing cannot be separated and therefore to use knowledge to its fullest potential it must be implemented, performed and enhanced'. Thus, it relies on active engagement, rather than passive experience of the setting for learning to take place. Moreover, the approach also accepts that learning is not confined to classroom environments; it also takes place in the workplace (Eames \& Bell, 2005; Helyer, 2015). Work placements are considered one of the best ways to develop students' transferable skills and understanding of employment (Helyer, 2015; Helyer \& Corkill, 2014; Jackson, 2015; Jackson \& Wilton, 2018). These experiences also develop students' networks and therefore help them to secure employment (Guile \& Lahiff, 2013).

In the context of undergraduate sport programmes, students are taught and rehearse skills and knowledge in classroom environments. These are often then transferred to controlled practical teaching spaces (e.g., practical coaching sessions or university lab spaces) where these skills can be rehearsed and sometimes assessed (e.g., Sato \& Laughlin, 2018). Moreover, sport students tend to undertake work placement modules and internships to practice and refine these skills further, thus applying theory to practice in real-world contexts (e.g., Sauder \& Davis, 2017). That said, to our knowledge, few placements across the sector are offered following an interview with the prospective work-placement provider; an essential skill for graduates seeking employment. Instead placement providers are typically contacted by the student who requests a short-term work placement opportunity which they either fulfil or refuse, or providers advertise short-term opportunities within their organisation and typically accept willing volunteers. Thus, a key learning processes for employability is being lost. That is, undergoing a (competitive) interview process where the student's knowledge, skills, qualifications and experiences are assessed for suitability in the role.

The benefits of experiential learning for graduate employability are well documented in various subject areas (Lategan \& Williams, 2019; Helyer \& Corkill, 2014; Jackson \& Collings, 2018), particularly sport (Cronin \& Lowes, 2016; Foster \& Dollar, 2017; Sato \& Laughlin, 2018; Sauder \& Davis, 2017). Therefore, we adopted this approach to conduct a small-scale teaching intervention that used mock job interviews as a form of assessment. Mock job interviews have previously been used in HE courses to prepare candidates for real employment interviews. For example, WittmannPrice et al. (2016) conducted 'simulations' of job interviews with their nursing students. However, interviews have rarely been used as a mode of assessment, especially in undergraduate sport programmes. This paper reports on a student-centred evaluation of this intervention, drawing upon the experiences of students who took part in it and the reflections of staff who conducted it. In doing so, we offer recommendations and highlight challenges for those seeking to adopt mock job interviews as a mode of assessment.

\subsection{Methods}

This paper draws upon the experiences of three final year undergraduate sports students who completed mock job interviews as a form of assessment on an optional 'Student Negotiated 
1 Learning' module ${ }^{2}$. As part of the module, students negotiated their learning outcomes, focus of 2 study and assessment mode with a supervisor allocated to them by the module leader. Over two 3 academic years, 27 students completed the module. Of these, three students completed mock job 4 interviews as a form of assessment on this module. The remaining 24 completed written pieces, 5 particularly literature reviews on their chosen topics. Somewhat different to previous sport-specific 6 employability research (e.g., Keech, 2006; Atfield \& Purcell, 2010), all three students had chosen to 7 study sport and exercise for vocational purposes. At the time of the interview-based assessment, 8 two of the participants, 'Jack' ${ }^{3}$ and 'Verity' were pursuing careers as secondary school PE teachers. 9 The third participant, 'Luke' was pursuing funding for postgraduate study in the development of 10 women's football. Thus, all three students would be interviewed by educational institutions to 11 proceed with their chosen career paths.

\subsection{The mock job interview assessment}

Each mock job interview was made specific to students' projected career, based on staff links to industry partners, prospective employers and postgraduate course leaders. The interview environment was set-up to mimic a real-life interview as closely as possible. Each interview had a student/candidate, an interview panel comprised of two staff members and a moderator to ensure assessment was fair across students. Each interview lasted 30 minutes. This was timed to ensure fair assessment conditions across students. A set of prepared questions were used to guide each interview and each interviewer was aware of which questions they would be asking prior to beginning. Questions were formed from a bank of questions collated from links with industry

\footnotetext{
${ }^{2}$ Most UK HEls operate a modular system of study. Degree courses are broken down into 'modules' each worth a number of credits or points. Each module has discrete content and assessment that compliments or contributes to the larger course of study. Some modules are compulsory, others are optional, but ultimately a student must obtain a set number of credits or points to obtain their qualification.

${ }^{3}$ Pseudonyms have been used to protect participants' identity.
} 
1 partners, course leaders, employers and/or publicly available practice questions. An example of the 2 interview questions used for prospective PE teachers is in Figure 1.

Figure 1. Example of questions for prospective PE teachers.

\section{Generic Questions}

Why do you want to become a teacher?

What qualities do you have that will make you a good teacher?

Do you have any concerns about being a teacher?

Do you feel you will be able to cope with the demands of a teacher trainer course?

\section{Skills and experience}

What skills could you bring to a school?

What teaching experience do you have?

-What did you enjoy?

-What did you find challenging?

-Can you think of an example of when you have helped a child in the classroom? Would you do this again? Would you do things differently?

\section{National curriculum knowledge}

What is the Curriculum for Excellence?

What are the most important issues in the current curriculum?

How is your degree relevant to the curriculum?

\section{Equal opportunities}

Should you be successful in your application and become a PE teacher, what types of inequality would you expect to face in your classroom? (Prompts: Internationalisation, Poverty)

How would you ensure students had equal opportunities in the classroom?

What are your thoughts on SEN classes in mainstream schools?

\section{PE specific}

What are the key elements of the PE curriculum (e.g., invasion games, exercising safely etc.) and how would you implement them?

What areas of the PE curriculum do you feel you need to improve on?

Are mixed classes or separate sex classes better?

\section{Scenarios}

What would you do if a pupil refuses to participate?

How would you motivate a group of students who have no interest in PE?

How would you challenge bullying in your classes/ changing rooms?

5 Candidates' answers were scored by each interviewer using the university's grading scheme and

6 feedback on how well the student responded was noted. The content of students' answers formed

7 the bulk of the marks (65\%). Students were expected to provide fully developed answers to

8 questions including examples of competence and experiences in their prospective field, in this case

9 either teaching or research. Interview rapport and etiquette (e.g., body language, eye contact, tone

10 and volume of responses) formed $35 \%$ of the marks. Students were deliberately not given instant

11 feedback to mimic real-life interviews. Instead, each set of feedback were combined and written

12 with a feedforward focus (see Wheatley, Lord, McInch \& Fleming, 2015). That is, specific 
1 recommendations for improvement in future interviews were provided. Students received feedback within one week of the interview.

\subsection{Evaluative procedures}

Once ethical approval for the research was granted and the mock job interviews were completed, students were contacted via email to ask if they would take part in an evaluative focus group on the teaching intervention. An information sheet outlining the aims and purpose of the research, the procedure and how data would be used was attached to the email. At this point, it was made clear that (non)participation in this study would not affect students' relationship with the university or staff and all participation was voluntary. To ensure power-relationships were less of an issue, the focus group took place after students had completed all assessments in their final year. All three students agreed to take part, all of whom were on a BSc (Hons) Sport Development and Coaching degree programme.

Accounts of semi-structured focus group methods were used to inform the data collection process (e.g., Sparkes \& Smith, 2014). The focus group was arranged at a time that was mutually convenient for all participants. It was held in a quiet semi-private room in the university to ensure they could speak freely. At the outset, participants were asked to re-read the participant information sheet, encouraged to ask questions about their involvement in the study and, if happy to continue, sign a voluntary informed consent form. An interview schedule was used to guide the discussion. This was structured into three parts. First, students' career plans and how university had prepared them for further study and or employment. Second, students' perceptions and experiences of mock job interviews as a mode of assessment. Finally, how this form of assessment might be adapted for future cohorts. At the time of the focus group, all participants had taken part in real-life interviews for their desired career and so could make comparisons between the assessment and a real interview. The focus group lasted 69 minutes and was recorded on a digital dictaphone. The recording was then transcribed verbatim.

Data were thematically analysed drawing upon Braun and Clarke's (2006) six-phase process as a guide. After, (re)reading and listening to the focus group, initial codes emerged (e.g., experience of interviews prior to assessment, experience of interview post-assessment, learning interview skills, work-based skills learnt in the classroom, usefulness of work placements, issues arising from work placements). All data pertinent to each code was identified. From these codes, broader overarching themes were identified, and data were sorted into thematic units of meaning - Skills and experiences for the work place, benefits of the interview assessment, challenges associated with the interview assessment and developing the interview assessment. These themes were then reviewed in relation to the study aim, which was to explore students' opinions of the interview assessment mode they had experienced, and overall coherence. Theme names were also reviewed and refined to better reflect the unit of meaning.

The findings of this research are presented in the form of realist tales (Van Maanen, 1988) as is common in much qualitative work (Sparkes \& Smith, 2014). This also maintains students' voice as much as possible. Staff reflections and analysis of this assessment mode are inherent in the reporting of this intervention as part of the overall analysis of the teaching intervention.

\subsection{Discussion of findings}

\subsection{Employability skills and experiences}


All participants suggested it was essential to have work experience to draw upon in interviews. Prior to the assessment, they had undertaken sport-specific work placements as part of their undergraduate course. Jack and Verity had both had two 20-hour placements in a high school PE department, and Luke had over 40 hours experience of working with a local sport development officer. The value students placed on these work placements was mixed. Sometimes students' found themselves either shadowing someone carrying out their role or placement providers misjudged the capabilities and experiences of the student resulting in an overwhelming experience. Others found an 'in at the deep end' approach advanced their learning, experience and confidence. Regardless of their experiences, students found placements useful for job interview purposes, indicating that work placement modules and internships in undergraduate sport programmes are highly beneficial in demonstrating professional expertise, a key determining factor in employers' hiring decisions (Humberg \& Van der Velden, 2015). Students were able to critically reflect on their experiences during these placements and draw upon these reflections in job interviews, thus illustrating experiential learning processes (Jackson \& Collings, 2018; Helyer, 2010).

\begin{abstract}
RL: How has university helped you prepare for interviews, or work more generally? Verity: I guess even though I didn't enjoy my placements as such, well they were a bit boring, I could still use what I saw and did on them at my interview.

RL: Jack you said you didn't like your work placement, but did it help?

Jack: The placement in first and second year... You were thrown right in at the deep end. And it's like here is a batch of Primary 3 kids, you're gonna teach them physical literacy for 6 weeks. It's just like whoa. I've never done this in my life... It wasn't great but I could use that to talk about how I might cope with difficult situations I guess.

Luke: I sort of had that situation, but I really enjoyed just being thrown in and I think, in terms of interviews, I can use that to demonstrate how I am quite adaptable. I think there are other things though, like I went to meetings and things and you can use that experience then to demonstrate times that you have had to present information to a different audience, things like that.
\end{abstract}

Further, participants' transferable skills that had been developed in classroom-based activities enabled them to thrive in their part-time employment and/or work placement. Communication and organisation skills were particularly noted in these discussions, as were practical, experiential learning opportunities. For example,

The experiences I've got in learning communication skills and organisation, things like that, have probably helped me out with university as much as they've helped me in university. So, gaining a coaching role or gaining a qualification, or something like that, has probably come from the communication skills l've built up, the knowledge obtained in classes and maybe the assessment systems involved in these.

(Luke)

...presentations that we've sort of been tasked with ... Not only gave me the confidence going out to meet new people, at conferences and gatherings, or even interviews or whatever. People ask you what your studying, what your researching etcetera and you can go on and express that. The more practical sides of university, so the presentations and the actual coaching or going out and doing things have helped a lot. (Jack)

Thus, whether they knew it or not, these students were operating within an experiential learning approach and were able to identify multiple examples of how their theory-based classroom activities 
had been applied to practical contexts, which, on reflection, had informed their learning and future development (Helyer, 2010). However, when asked, none of the participants felt they had adequate experience of job interviews specific to their prospective career paths. For example:

Verity: I had had interviews for part-time work, like my job at [Supermarket], but until Student Negotiated Learning [module title] I didn't know much about the Postgrad teaching interview process. It's obviously not the same as an interview for a shop or something; it's quite specific. We haven't really covered anything to prepare us for it. RL: Jack? Jack: Well I'd spoken to teachers that I've met on placements and stuff, but not really. It's different actually doing it, isn't it?

Luke: Yeah. For me, I didn't really know what an interview for a master's programme would be like.

Even with probing around transferable skills and how they might link to interviewing, participants still felt interview skills were different to other transferable skills they'd learnt and practiced at university.
RL: Jack, you said that you had learnt some communication skills and techniques in presentations. Do you think these would help you in an interview? Jack: Well yeah, a bit. Like, it helps with speaking in front of people you don't know, but a presentation is mostly one way isn't it? It's not like an interview, well not the same. I don't know, I think it's a different skill.
Luke: I think the same. I'd say my communication skills are quite good now and we've done quite a bit to practice this over the years, but I still think it's different in a job interview somehow. It's maybe the set-up or something.

To probe this point even further, the interviewer asked participants if they noted any similarities in interviewing as a research method and interviews within the context of employment. Again, participants suggested that there was a different skill set required.
RL: What about when you learnt about interviewing in research methods or did interviews for your final year project? Did this help you to prepare for job interviews? Luke: Hmmm. It's different. I see what you mean. It should, but it's different. The interviews I did [for final year project] were me trying to get information from people, so it's the other way around. I guess I've probably learnt how to interview someone for a job! Verity: I know what you mean. It is different. I think as well that, research interviews are more informal, 'tutor name' taught us that they should be informal and job interviews are formal, so it is quite different.

Thus, participants in this study had all reached the final year of their studies having had at least 40 hours on work-based experience in their chosen field. They were also able to identify examples of transferable skills that would be needed in their future employment including job interviews and identify where and how these skills had been taught and assessed on these across their curriculum. Yet, despite some of the core skills identified being needed for job interviews (e.g., communication and presentation), participants still felt underprepared for job interviews. This perception stemmed from lack of opportunities to adapt, rehearse and refine their existing skills to the specific context of a job interview. This was then linked to participants' rationale for them selecting this as a mode of assessment:

\section{RL: Why did you chose to do interviews as a form of assessment?}


Verity: Well I didn't know it was even an option until we had our meeting [to negotiate the topic and assessment]. It was only because I asked you for a reference at the same time, that you said I could do a mock interview. And I thought, well that would be good because I've never done a proper interview before, at least not for teaching so I had no idea what to expect. When you think about it, it's a bit odd; doing all the work placements, but do that and it's just not the same as doing say a presentation. I felt completely unprepared and it was going to happen in like two month's time. I just needed to see what it was like; like a practice.

Thus, combinations of limited interview experience, looking or applying for roles requiring industryspecific interviews and staff suggestion contributed to students' rationale for undertaking mock interviews for assessment. It is important to note that students on the module could approach any member of sport staff $(n=12)$ to negotiate their topic and assessment and therefore suggestions for alternative, non-written forms of assessment may have been driven by staff with experience of this type of assessment. However, other students $(n=4)$, across the two academic years, were offered the same opportunity but declined. Thus, students ultimately made their decision to undertake this assessment based on their limited experience of industry-specific interviews.

\subsection{Mock job interviews as an assessment mode: Benefits and challenges}

All participants highlighted various benefits of the interview assessment. They saw job interviews as an essential step to the next element of their career, yet claimed the teaching, practice and assessment of interview skills were neglected in various educational contexts including HE. For example:

I'd never had an assessment like it before. Not at university, not at college or school. And some of the sport interviews, like for teaching, are not the same as other interviews. It's weird really to think that we've spent years learning about sport development or coaching and teaching for you [to Jack and Verity] and we've done placements, but until this we haven't actually done anything on how you actually get a job in those fields. It's pretty essential isn't it and I'd rather mess it up here, at uni, then when it matters most. I'm glad we did it [the assessment].

(Luke)

Participants indicated that the ways in which the interviews were set-up presented a relatively safe space to make mistakes. They felt it was a useful learning space and there was evidence in the focus group discussions that experiential learning processes had allowed them to learn come coping techniques for overcoming interview-based anxiety often experienced by (under)graduates in job interviews (Feeney et al., 2015).

Jack: It didn't matter if you messed up. Well, it was an assessment so...(pause), but you know what I mean, it's not like it was life-changing for your career if it went horribly wrong. Verity: Yeah, I was glad it wasn't the real thing. But at least I know what it's going to be like and what to avoid [saying/doing] now. I think in mine as well, I had a bit of a blank moment, but Assessor 2 just said to take my time and have a drink of water. It was better that happened here than at my interview.

In addition, in and through this learning space, academic staff who acted as the interview panel were often viewed as critical friends rather than assessors. Students felt the feedback they received from this activity was meaningful and constructive, perhaps more so than other feedback they'd had. 
Jack: I've known 'Assessor 1' for what three years, and I know 'they' were trying to help me. So, the feedback, I knew it was 'them' wanting to help me to get through my actual interview. I probably took it more seriously because of that, well and I knew I had my actual interview coming up as well. So, when I got my feedback, I was straight in there reading it, so I knew what to say and what not to say.

$R L$ : So, do you normally read your feedback; in the same way? Jack: [Laughs]. No, I don't know, urgh... I probably read my feedback more if I'm disappointed with my grade. If I see a B or something, then I probably skim it. But with this it was different, because I knew I had my interview coming up.

(Jack)

Jack's comments are not dissimilar to others' findings on how students have traditionally engaged with tutor feedback (e.g., Duncan, 2007; Price, Handley, Millar \& O'Donovan, 2010). However, assessors were conscious of providing recommendations for future interviews as well as an explanation for the grade awarded and thus there was an emphasis on feeding forward in feedback (Wheatley et al., 2015). As part of this process, students not only internalised suggestions for future practice, but also assessors' comments about good performance. Participants claimed this helped them recognise their strengths and increased their confidence.

There was stuff in there [feedback sheet] that really helped me. Like I always thought I was awful at speaking in presentations and things, but the feedback gave me some confidence that I wasn't as bad as I felt. It was a confidence boost before my interview and I worried about it less in my interview. I don't think I thought, you know, am I mumbling or being quiet. And my feedback after [the real interview] was that I was clear and confident, so... (Luke)

A core element of the focus group was dedicated to determining how closely the interview assessments represented the interviews students had experienced as this was a key concern for staff when setting up the interview assessments. Students' responses to these questions revealed a good level of similarity between the assessment and real-life interviews.

Luke: Mine was pretty much exactly the same. Same number of people interviewing, same sort of questions. I think some of them were exactly the same, but I was applying for a masters here, so I guess you know more about what is going to happen, but with you [gesture to Jack] I suppose it depends which uni you were applying to as to how they do things and what questions you get.

Jack: It was quite similar to the interview I had. It was the same sort of questions. I felt quite nervous before [the assessment] and this probably helped when I felt nervous for the interview; I knew it was just a bit of nerves. It's not exactly the same, but it was really good for practice.

Jack's comments also illustrate one of the main challenges of the assessment. Students had limited experience of this or similar types of assessments and this was the source of some anxiety:

Jack: The run up to it was quite nerve wracking. I just didn't know what to expect. Verity: Me too. I was glad you told me to look at those websites for practice questions otherwise I wouldn't have known what to prepare. It's not like we were taught any content on the module, so it was really up to us to prepare and look into the process. Obviously staff guided us on what to look at but we weren't really taught as such, not like other modules. 
Jack: But that was good in some ways. At least we knew where to look for that type of information for our actual interviews and we could ask for help [from staff]. Verity: I still felt sick beforehand though. It was just nerves. It's silly now, but at the time I just felt awful. Stupid things as well like what to wear (laughs). Jack: But again, at least that all helped for our actual ones.

Thus, the interview assessment assisted students' experiential learning by providing opportunities on how to prepare for interviews, how to cope with interview-based stress and nervousness and interview etiquette (e.g., appropriate attire). However, although the module is designed to encourage independent learning, staff have reflectively noted that because of the somewhat alien nature of the task, student undertaking this assessment in the future might require more guidance on how to prepare and what content to prepare (e.g., a set of practice questions and information on interview processes).

In sum, students' experiences of this assessment suggest that this was a highly beneficial experiential learning opportunity. The mock job interviews were constructed to produce a safe learning space for the students and feedforward focused feedback enabled students to critically reflect on their experience to inform future job interviews. Moreover, the interviews presented a good deal of symmetry to real-world interviews in the field, presumably because of tutors' close connections with industry partners.

\subsection{Student-led development of the interview assessment}

Student experience is increasingly shaping curriculum and module design in HE. Some HEls have embraced the idea of collaboration with students to develop or create curricula (e.g., Delpish et al., 2010). In this spirt and to add the student voice to the ongoing debate and discussion of student employability, we asked students about how this assessment mode might be developed for future cohorts and/or created for other groups of students. Some of their suggestions might be logistically challenging within the context of HE teaching (e.g., complex timetables, limited space and limited time), but their thoughts offer curriculum designers and teaching staff thought-provoking ideas for the implementation and development of interviews as a form of assessment.

Participants felt that this form of assessment would be beneficial to all undergraduate sport students and suggested that this assessment mode be made compulsory perhaps in work placement modules. They felt this would offer a more meaningful assessment rather than reflective essays, which are common in these modules, but are key in assessing the level of students experiential learning. For example, Verity said:

We did some good things, like creating an online profile or CV type of thing, that was in first year I think, or second, and actually going out on placements, but we also did quite a few reflective essays. It was okay, but it was just a bit boring. If I'm honest, it didn't really make me think about what l'd learnt or what I was going to do as a result of doing that assessment. I think an interview would be more beneficial. Why doesn't everyone do it [interview assessment]? In their last year it would be good. (Verity)

Students also felt that the space in which the assessment was conducted was important. Due to timetabling constraints, the assessments took place in small teaching classrooms. In the focus 
group, students discussed this space and determined, that if possible holding this assessment in a more formal space such as a boardroom might further prepare them for a real-life interview. In particular, they felt it might help future students learn to cope with interview-based anxiety.

If mine had been in the boardroom, I probably would have felt more nervous, because it's actually like a real interview room. I suppose that might make some people too nervous, but surely it's best to have a real taste of what it's going to be like? (Luke)

Linked to issues of appropriate space, were discussions around the length of time of the assessment lasted. The students agreed that 30 minutes was a good length of time and this mimicked the experience they' $d$ had in real-life interviews. However, with earlier suggestions of this activity being expanded to other final year undergraduate sport students, that is approximately 100 students in our institution, the interviewer asked if shorter interviews would offer a similar experience. However, participant responses suggest that this would not be favourable as interviews would lose their authenticity.

RL: Okay, so if this was going to be rolled out to everyone, we [staff] probably wouldn't be able to do half an hour interviews, they'd probably have to be shorter. So, what do you think about a 15-minute interview? Verity: I don't think it would be the same experience. Jack: No. I think this assessment was good because I felt I was getting a proper grilling (Laughs). (Group laughs). No, ok, so I felt like we were actually having time dedicated to our development, if you know what I mean. Like it was an actual practice for the real thing. If it was shorter, like 15 minutes, it's not really going to be like the real thing. I think it loses the point then.

Participants also suggested that making interviews specific to the job interview associated with their prospective career was essential for a meaningful assessment and learning opportunity. For example, those wishing to purse a postgraduate course in teaching after their degree should undertake an interview assessment that is similar in content and structure to postgraduate course interviews. The suggestion of a more generic interview was less favourable.

$R L:$ What about a more generic interview? One where you get one or two interviewers and a set of generic competency-based questions. That would still give you the same skills for interviews wouldn't it?

Luke: Yes, but it's not really the same is it? It would help a bit maybe with things like nerves and stuff, but...

Jack: Nah. The PGDE interview is quite specific. Like it has a panel of interviewers, I think there were five, yes five at mine and they ask you about teaching not general stuff really. Luke: I also think, like I don't want to do teaching, so if we were all made to do teaching interviews it would be pointless for me.

$R L$ : Don't you think you could take away something from it? There are some transferable skills...

Luke: Yes, but I don't think I would've engaged with it the same. If I thought about interview skills and interview skills, but I think some people wouldn't really think about it like that, even if you told them.

Moreover, participants felt that the interview could have extended to further mimic real-world interviews in their chosen field. 
It would have been good to do a mock of the practical teaching part of the interview as well. I know we sort of do this in coaching, well it's pretty much the same, but if you did it as part of the interview, well, that would be like a practice of the whole thing. I know that would probably be hard for you guys to fit everyone in though (laughs).

(Jack)

Based on students' suggestions, this assessment mode presents some real challenges for teaching practitioners who wish to embed this assessment mode across a large cohort or module, particularly if there is a small team of assessors who have limited time and space to complete assessments. Moreover, the interviews we conducted were similar to real-life interviews in the students' prospective career pathways because our staff links to industry partners. Sport students are employed in a vast range of industries and roles (Minten \& Forsyth, 2014) and therefore making interviews specific to their ideal employment would be challenging, if not impossible.

\subsection{Recommendations and concluding thoughts}

There is an increasing focus on embedding graduate employability skills across global HE curricula (Kalfa \& Taksa, 2015; Pavlin \& Svetlik, 2014; Pegg et al., 2012) including undergraduate sport programmes. Work placement modules across curricula are often used to develop students' transferable skills for employment and help them to develop experience of the workplace. These modules offer experiential learning opportunities which are beneficial for graduates learning and securing later employment (Guile \& Lahiff, 2013; Helyer \& Corkill, 2014) particularly at interview (Humberg \& Van der Velden, 2015). Yet fundamental experiential learning opportunities are being lost in the processes sport students tend to undergo to obtain work placements. They rarely undertake occupation-specific job interviews to obtain these placements. Students in this study perceived subtle nuances in how transferable skills (e.g., communication and presentation skills) are performed in job interviews and practicing of this was absent from their education both in terms of learning and assessment. Offering this opportunity to students undertaking a small module that encompasses a flexible learning and assessment strategy led to a highly beneficial learning experience. Students learnt to adapt their existing skill-set to a job interview context that was specific to their chosen career and obtain feedback with a feedforward focus. Thus, they perceived this to be one of their more meaningful and constructive assessments.

Student feedback suggests that this might be a pertinent mode of assessment for future cohorts of sport students. However, this is not without its challenges. Within the context of modern HEls, there are logistical issues around teaching time and space in which to conduct mock job interviews as a form of assessment. Moreover, (sport) students enter a vast range of industries and job roles (Minten \& Forsyth, 2014) and therefore offering interviews that are appropriate in structure and content would be dependent on the links teaching staff have with industry partners. Following this research, we have continued to offer this opportunity for future students on our Student Negotiated Learning module in the same format. In addition, we have embedded interviews into all our extracurricular student internship opportunities. Often industry partners are directly involved in these by attending and interviewing candidates alongside academic staff. Thus, we are expanding the use of this experiential learning opportunity into other areas of academic life.

For this mode of assessment to be effective, we argue that practitioners seeking to adopt this mode of assessment, first establish a range of interviews types that are appropriate for their students (e.g., interviews for postgraduate courses in teaching, interviews for postgraduate research degrees, interviews for sport development coordinators etc.). Second, teaching staff should seek out advice 
from industry partners. This leads to teachers' refreshed knowledge of interview processes and employer expectations, and opportunities for industry partners to become involved in the interview assessment either directly by attending in person or indirectly by providing example interview questions. Third, practitioners need to mimic interview contexts and conditions as closely as possible to give students an effective experience. Finally, feedback must have a feedforward focus to make the activity as meaningful as possible.

Interviews as a form of assessment, particularly in undergraduate sport courses, remain an underresearched pedagogical tool, one that requires further attention. This paper provides an example of a small-scale pedagogical intervention with a small sample to address this issue and in doing so aims to start discussion on the missed opportunities of preparing our students for a pinnacle moment in obtaining employment - the job interview. However, the sample size, although $100 \%$ of the potential pool of participants, gives us a somewhat limited understanding of (sport) student experiences of mock interviews as a form of assessment. While qualitative work lends itself to small sample sizes (Sparkes and Smith, 2014), a larger sample of students' views captured by a less familiar researcher would develop our understanding. In addition, future studies might wish to explore why students do not engage in these types of opportunities when given the option. In addition, we know very little about how students engage with career services departments in HEIs for the purpose of preparing for interviews; something which our participants did not comment on.

\section{References}

Association of Graduate Careers Advisory Services. (2007). What do Graduates do? 2008 Career planning for higher education and beyond. AGCAS in association with the higher education career services unit.

Atfield, G., \& Purcell, K. (2010). Graduate labour market supply and demand: Final year students' perceptions of the skills they have to offer and the skills employers seek. Institute for Employment Research: University of Warwick.

Braun, V., \& Clarke, V. (2006). Using thematic analysis in psychology. Qualitative research in psychology, 3(2), 77-101.

Clarke, M. (2018). Rethinking graduate employability: The role of capital, individual attributes and context. Studies in Higher Education, 43(11), 1923-1937.

Cronin, C. J., \& Lowes, J. (2016). Embedding experiential learning in HE sport coaching courses: an action research study. Journal of Hospitality, Leisure, Sport \& Tourism Education, 18, 1-8.

32 Dearing, R. 1997. Higher Education in the Learning Society. Report of the National Committee of Enquiry into Higher Education. London: HMSO.

Delpish, A., A. Darby, A. Holmes, M. Knight-McKenna, R. Mihans, C. King, and P. Felten. 2010. Equalizing voices: student faculty partnership in course design. In Werder, C. and M. Otis. (Eds) Engaging student voices in the study of teaching and learning. Virginia: Stylus

Department of Business Innovation and Skills. (2009). Higher Ambitions: The Future of Universities in a Knowledge Economy. London: DBIS. 
Eames, C., \& Bell, B. (2005). Using sociocultural views of learning to investigate the enculturation of students into the scientific community through work placements. Canadian Journal of Math, Science

3 \& Technology Education, 5(1), 153-169.

4 Feeney, J. R., McCarthy, J. M., \& Goffin, R. (2015). Applicant Anxiety: Examining the sex-linked 5 anxiety coping theory in job interview contexts. International Journal of Selection and 6 Assessment, 23(3), 295-305.

7 Foster, S. B., \& Dollar, J. E. (2017). Experiential learning in sport management: Internships and 8 beyond. Morgantown, WV: Fitness Information Technology.

9 Jackson, D. (2015). Employability skill development in work-integrated learning: Barriers and best practice. Studies in Higher Education, 40(2), 350-367.

Jackson, D., \& Bridgstock, R. (2018) Evidencing student success in the contemporary world-of-work: renewing our thinking, Higher Education Research \& Development, 37(5), 984-998.

Jackson, D., \& Collings, D. (2018). The influence of Work-Integrated Learning and paid work during studies on graduate employment and underemployment. Higher Education, 76(3), 403-425.

Jackson, D., \& Wilton, N. (2017). Perceived employability among undergraduates and the importance of career self-management, work experience and individual characteristics. Higher Education Research \& Development, 36(4), 747-762.

Kalfa, S., \& Taksa, L. (2015). Cultural capital in business higher education: reconsidering the graduate attributes movement and the focus on employability. Studies in Higher Education, 40(4), 580-595.

Keech, M. (2006). Placements and employability in sport and leisure management. In N. Beckett, \& P. Kemp (Eds.), Enhancing graduate employability in business and management, hospitality, leisure and sport, tourism. Newbury: Threshold Press.

Kirschenman, J., \& Neckerman, K. M. (1991). We'd love to hire them, but...": The meaning of race for employers. The urban underclass, 203, 203-32.

Koch, A. J., D'mello, S. D., \& Sackett, P. R. (2015). A meta-analysis of gender stereotypes and bias in experiential simulations of employment decision making. Journal of Applied Psychology, 100(1), 128.

Guile, D and Lahiff, A. (2013) Internship: Conventional Wisdom, Models \& Recommendations. London: Institute of Education, University of London.

Helyer, R. (Ed.) (2010). The Work-Based Learning Student Handbook. Basingstoke: Palgrave Macmillan.

Helyer, R. (2015). The work-based learning student handbook. Macmillan International Higher Education.

Helyer, R. \& Corkill, H. (2014) Experiential Learning Survey, unpublished.

Helyer, R., \& Lee, D. (2014). The role of work experience in the future employability of higher education graduates. Higher Education Quarterly, 68(3), 348-372.

Hogue, M., Levashina, J., \& Hang, H. (2013). Will I fake it? The interplay of gender, Machiavellianism, and self-monitoring on strategies for honesty in job interviews. Journal of Business Ethics, 117(2), 399-411. 
1 Humburg, M., \& Van der Velden, R. (2015). Skills and the graduate recruitment process: Evidence 2 from two discrete choice experiments. Economics of Education Review, 49, 24-41.

Lategan G., Williams M. (2019) Student Learning and Employability: Immersion in Live Events. In Beeton S., Morrison A. (Eds.), The Study of Food, Tourism, Hospitality and Events. Tourism, Hospitality \& Event Management (pp.133-142). Singapore: Springer

Lindsay, S., McDougall, C., Menna-Dack, D., Sanford, R., \& Adams, T. (2015). An ecological approach to understanding barriers to employment for youth with disabilities compared to their typically developing peers: views of youth, employers, and job counsellors. Disability and rehabilitation, 37(8), 701-711.

McCarthy, J. M., Van Iddekinge, C. H., \& Campion, M. A. (2010). Are highly structured job interviews resistant to demographic similarity effects?. Personnel Psychology, 63(2), 325-359.

McKeown, T., \& Lindorff, M. (2011). The graduate job search process-a lesson in persistence rather than good career management?. Education and Training, 53(4), 310-320.

Minten, S., \& Forsyth, J. (2014). The careers of sports graduates: Implications for employability strategies in higher education sports courses. Journal of Hospitality, Leisure, Sport \& Tourism Education, 15, 94-102.

Moore, T., \& Morton, J. (2017). The myth of job readiness? Written communication, employability, and the 'skills gap'in higher education. Studies in Higher Education, 42(3), 591-609.

Pavlin, S., \& Svetlik, I. (2014). Employability of higher education graduates in Europe. International journal of Manpower, 35(4), 418-424.

Pegg, A., Waldock, J., Hendy-Isaac, S., \& Lawton, R. (2012). Pedagogy for employability. York: Higher Education Academy.

Price, M., K. Handley, J. Millar, and B. O'Donovan. (2010). Feedback: All that effort, but what is the effect? Assessment \& Evaluation in Higher Education 35(3), 277-89.

Rivera, L. A. (2015). Go with your gut: Emotion and evaluation in job interviews. American journal of sociology, 120(5), 1339-1389.

Sato, T., \& Laughlin, D. D. (2018). Integrating Kolb's Experiential Learning Theory into a sport psychology classroom using a golf-putting activity. Journal of Sport Psychology in Action, 9(1), 51-62.

Sauder, M. H., \& Davis, D. (2017). Exploring the relationship between early experiential learning and capstone internship outcomes in sport management education. International Journal of Sport Management, 18(2), 210-239.

Sleap, M \& Reed, H. (2006) Views of sport science graduates regarding work skills developed at university. Teaching in Higher Education, 11(1), 47-61.

Sparkes, A. C., \& Smith, B. (2014). Qualitative research methods in sport, exercise and health: From process to product. Oxon: Routledge.

Taylor, M. (2017). Good Work. The Taylor Review of Modern Working Practices. Retrieved from https://www.gov.uk/government/publications/good-work-the-taylor-review-of-modernworking-practices 
2 Tran, T. T. (2015). Is graduate employability the 'whole-of-higher-education-issue'?. Journal of

3 Education and Work, 28(3), 207-227.

4 Tsitskari, E., Goudas, M., Tsalouchou, E., \& Michalopoulou, M. (2017). Employers' expectations of 5 the employability skills needed in the sport and recreation environment. Journal of hospitality,

6 leisure, sport \& tourism education, 20, 1-9.

7 Van Maanen, J. (1988). Tales of the field. On writing ethnography. Chicago: Chicago University Press.

8 Wilson, T. (2012). A review of Business-University Collaboration. Retrieved from

9 http://dera.ioe.ac.uk/13842/1/wilson.pdf

10 Wittmann-Price, R. A., Price, S. W., Graham, C., \& Wilson, L. (2016). Using simulation to prepare 11 nursing students for professional roles. Holistic nursing practice, 30(4), 211-215.

12 Wheatley, L., Lord, R., McInch, A., \& Fleming, S. (2015). Feeding back to feed forward: Formative 13 assessment as a platform for effective learning. Kentucky Journal of Higher Education Policy and 14 Practice, 3(2), 1-31.

15 Whiteley,S.(2016).Creating a coherent performance indicator framework for the higher education 16 student lifecycle in Australia. In R. Pritchard, A. Pausits, \& J. Williams (Eds.). Positioning higher 17 education institutions (pp. 143-160). Rotterdam, NL: Sense Publishers.

18 Wolgast, S., Björklund, F., \& Bäckström, M. (2018). Applicant Ethnicity Affects Which Questions Are 19 Asked in a Job Interview. Journal of Personnel Psychology, 17, 66-74. 